\title{
Monitoring of Forest Area Change using Satellite Data with Special Emphasis on Sungai Buloh Forest Reserve, Malaysia
}

\author{
Kamaruzaman Jusoff*
}

\begin{abstract}
This paper features the utilization of satellite remote sensing in monitoring of forest area changes for timber resource management planning. Landsat TM data was applied to the monitoring and estimation of future forest area in Sungai Buloh Forest Reserve. Quantification of forest changes due to urbanization was performed using the dot technique with multi-temporal data taken in 1989, 1991 and 1994. On the present trends, the forest area is projected to be reduced to 1,450ha by the year 2000 and 615 ha by 2005. The forest in Sungai Buloh will be completely exhausted by the year 2011 if forest conservation practices are not implemented.
\end{abstract}

keyword: forest, monitoring, satellite data

\section{INTRODUCTION}

Only a few reports have so far dealt with the primary productivity of tropical or equatorial forests but there is already enough evidence to show that the methods for assessing area changes are essentially the same in both temperate and tropical forests. KIRA et. al. (1967) and Hazumi et. al. (1969) successfully applied the techniques which had been developed in temperate forest studies to estimate productivity in tropical forests of Africa and South-East Asia.

Visual and digital interpretation of satellite remote sensing has been the principal technique for estimation of the areas of stands in almost all tropical forest inventories (UNESCO, 1978; KamaruZaman and Abdul HaYe, 1993; Kamaruzaman and Rasol, 1995). This applies equally to inventories at national and sub-national level; as well as to pre-investment surveys for the granting of large concessions. The interpretation of satellite imagery is also used for the classification of forest stands according to criteria linked to their development, such as different types of forest, accessibility classes, density height of dominant

\footnotetext{
* Remote Sensing/GIS Research Group, Faculty of Forestry, Universiti Putra Malaysia, 43400 UPM, Serdang, Selangor, Malaysia
}

canopy trees, etc. Some of these criteria are equally useful in stratification which permit a more precise estimation of the average unit area characteristics for both total and partial forest inventories. This interpretation can be supplemented by additional information on boundaries separating administrative units and on types of tenure.

The objective of the study is therefore to monitor, estimate and predict the forest area in Sungai Buloh Forest Reserve using satellite remote sensing .

\section{METHODS AND MATERIALS}

Description of Study Area

The study site was chosen in Sungai Buloh Forest Reserve (FR). This reserve is situated in the Mukim of Sungai Buloh which forms part of the overall administrative District of- Petaling in the State of Selangor Darul Ehsan (Fig. 1). Although the current state of the site is largely forested and sparsely populated, the,forest reserve is located close to major urban centers such as Kuala Lumpur ( $12 \mathrm{~km}$ to the east), Shah Alam (12km to the west) and Port Klang ( $18 \mathrm{~km}$ to the west), Petaling Jaya (19km to the south east) and Sultan Abdul Aziz Shah International Airport ( $11 \mathrm{~km}$ to the south east). 


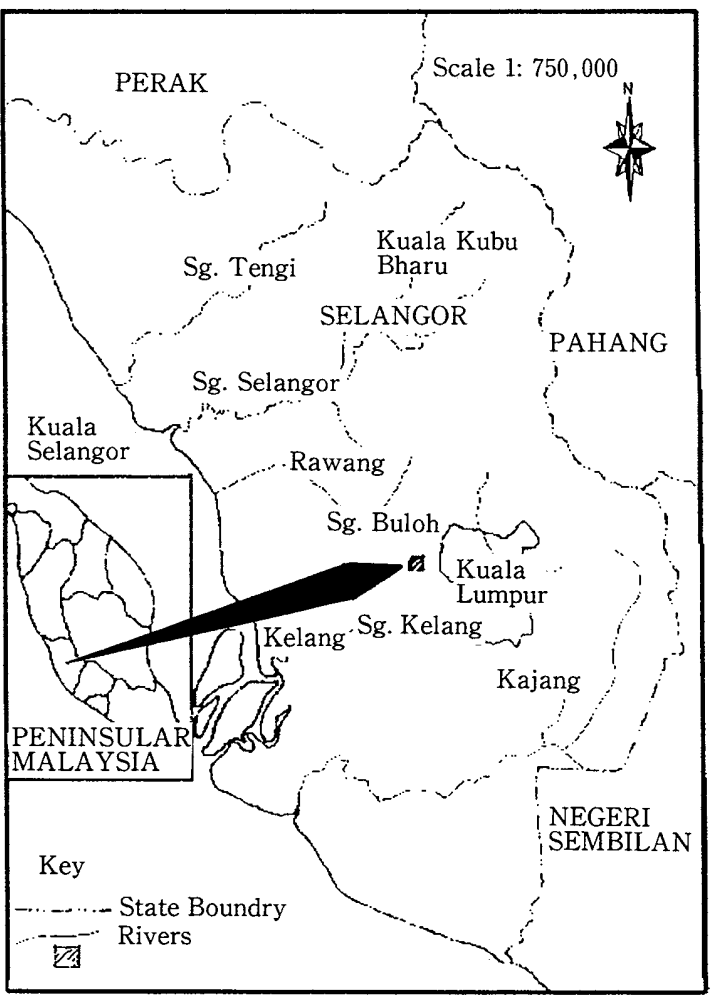

Fig. 1 Location of study area

The forest cover in the study area can be classified as the 'Red Meranti Keruing Forest' (Wyatr-Smith, 1963). The forest is reasonably rich with a high percentage of commercially important species of Shorea. The mean basal area of the forest inclusive of all species groups was estimated to be $26.9 \mathrm{~m}^{2}$ /ha (ANON, 1987).

For the purpose of predicting forest productivity of the study site, a wider study area covering $25 \mathrm{~km} \times 25 \mathrm{~km}$ was selected to detect the forest cover change reduction occurring from 1989 to 1994 (Fig. 2).

\section{Topography}

The Forest Reserve is undulating, ranging from about 30 to 333 m.a.s.1. The highest peak is Bukit Lanjan which is responsible for the hilly nature of the area, and several streams originate from this ridge, forming small valleys and swampy land in the lower reaches. The area is drained westerly by the Sungai, northerly by the Hampar and southerly by Sungai Rumput and its tributaries in the central and southern part. Fig. 2 showed the land use in the Mukim of Sungai Buloh which is generally agricultural, covering about $51.5 \%$ of the total land use.

\section{Geology and Soils}

The study area is almost entirely underlain by granitic bedrock, though the surficial soils are of variable

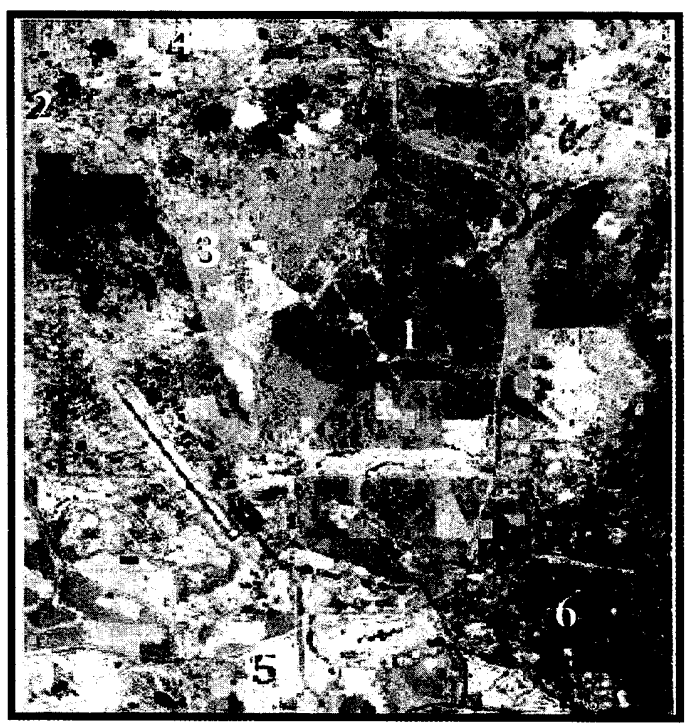

1-Forest 2-Oil Palm 3-Rubber

4-Grassland 5-Bareland 6-Urban

Fig. 2 Landsat TM image of study area

textures, dependent upon topographic location. In the undulating and hilly areas, granitic residual soils are present, while along the flood-plains and terraces of the rivers, unconsolidated fluvial sediments are found.

Several varieties of granitic bedrock are present in the area and include both porphyritic and non-porphyritic ones. All of these granitic rocks are moderately to highly fractured and are cut by several faults. Several quartz veins and dikes are found within the study area with the veins being some 1 to $5 \mathrm{~cm}$ thick, while the dikes are some 20 to $30 \mathrm{~m}$ thick. A hot spring has also been reported to be present at the point where the Sg. Rumput intersects the longest quartz dike, though this has now been covered by tin-tailings.

The general soil strata forming the eastern fringe of the study area comprises a top stratum of residual soil of sandy clay / silt to clayey silty sand with subangular to angular quartz gravels derived from the weathering of granite rock.

\section{Climate}

The mean annual rainfall between 1966 and 1985 was $2,282 \mathrm{~mm}$ falling over 193days of the year. Most of the precipitation occurs between the months of October and December and March to April. The period from June to August is the driest.

Annual temperatures are relatively uniform averaging about $26.4^{\circ} \mathrm{C}$. The daily mean maximum and minimum temperatures are $32.1^{\circ} \mathrm{C}$ and $22.7^{\circ} \mathrm{C}$ respectively. The high- 
est temperatures occur between April and June, and the lowest between November and January. The mean daily relative humidity is high with an annual mean of $83.9 \%$ and fluctuates between $50 \%$ and $99 \%$. The relative humidity is highest in November and December, and somewhat lower between March and August.

Materials

\section{Data Acquisition}

Three Landsat digital spectral images taken on 15th

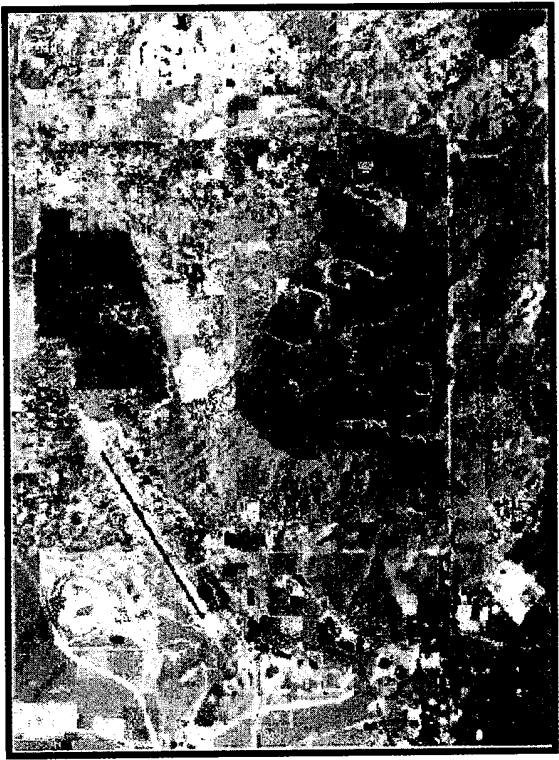

Fig. 31989 image of the study

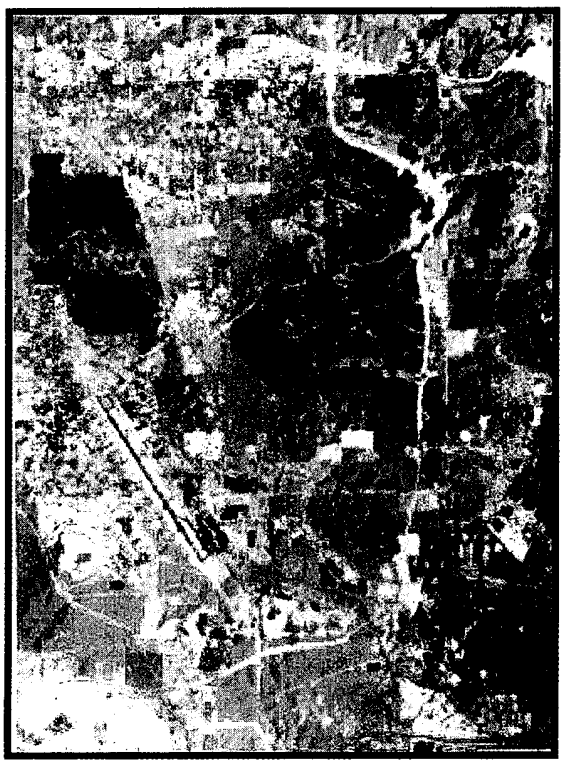

Fig. 41991 image of the study area
February, 1988, 21st February, 1991, and April 1994 (path/ row 271/58) were used. The satellite imageries were bought from Malaysia Center for Remote Sensing (MACRES). These scene had covered with less than 5\% cloud cover and have been corrected for atmospheric haze. The multi-temporal images are shown in Fig. 3, 4 and 5.

Methodology

The area of Sungai Buloh Forest Reserve was determined by the use of satellite imagery and the Dot Technique. With this technique, satellite image were overlaid with a dot grid sheet to obtain forest area. The dot grid sheet contains squares where each square contains 100 dots. Each dot representing the area of forest was based on the satellite imagery scale. The scale of satellite imagery used was $1: 200,000$ and due to the scaling conversion, a multiplier factor of 6.44 was used to estimate the forest area with each dot overlaid on the forest area derived from satellite imagery.

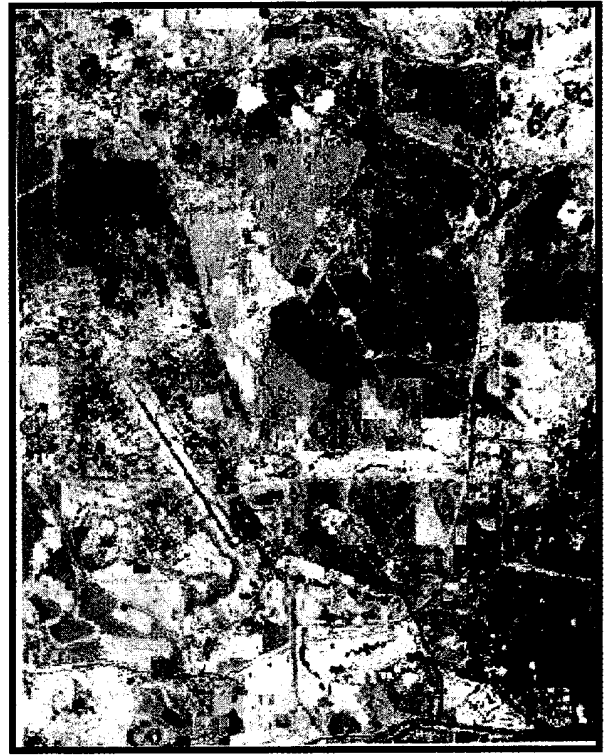

Fig. 51994 image of the study area

Table 1 Forest area estimate of study area

\begin{tabular}{|c|c|}
\hline Year & Forest Area (ha) \\
\hline 1989 & 2,763 \\
\hline 1991 & 2,222 \\
\hline 1994 & 1,971 \\
\hline
\end{tabular}




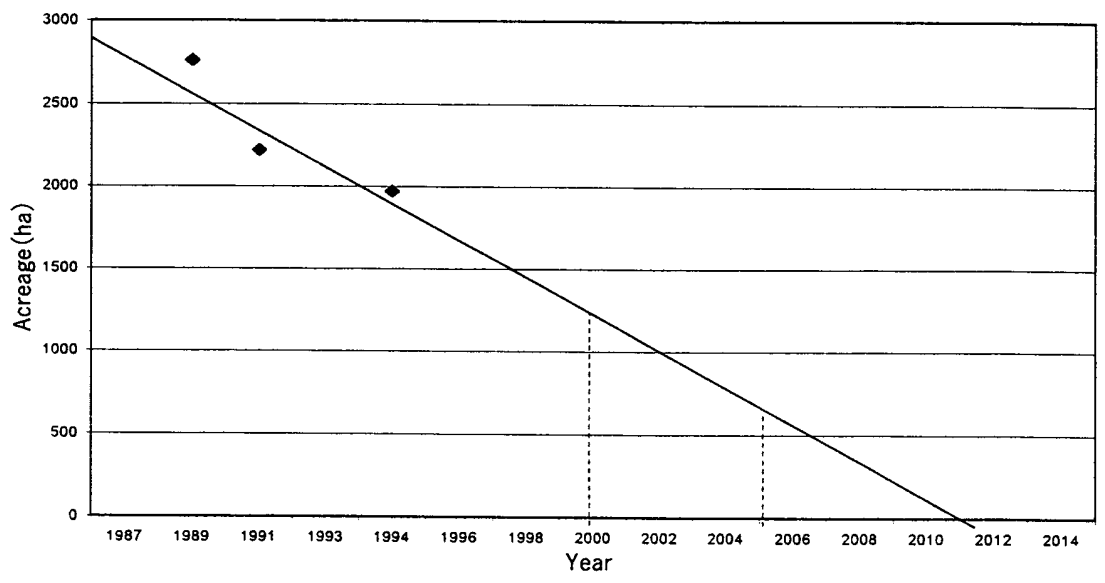

Fig. 6 Projection of forest area in Sungai Buloh Forest Reserve

\section{RESULTS AND DISCUSSION}

By using the dot technique, it is possible to calculate the area of forest in the study area. The forest areas for 1989, 1991 and 1994 were 2,763ha, 2,222ha and 1,971ha, respectively as shown in Table 1 .

For the purpose of predicting future forest area, a graph of forest area versus years was plotted and a straight line was fitted to the points (Fig. 6). On the basis of the declining trend of this graph, it was estimated that the forest area will declined to 1,450ha by the year 2000 and to 615 ha by year 2005 . The projection indicates that if the area is continuously reduced and opened up for urban and other land uses, there will be no forest left in Sungai Buloh Forest Reserve by the year 2011 .

\section{CONCLUSION}

Satellite remote sensing is becoming more widely used in predicting forest area. The case study in Sungai Buloh Forest Reserve demonstrates the role of satellite data as an effective tool to predict future forest area with aid of other data.

Continuous forest monitoring should also indicate trends in regional and world wood production and could give an overview of the roles of these forests as raw material producers and as protectors of the environment.

National forest inventories, on the other hand, must not be limited to the inventory of available growing stock and growth rate, but must link these to ecology and floristic composition of the forest stands. To be effective, inventories must not neglect ground operations, which are often complex. Problems which require further study, include sampling methodology, extraction systems, terrain classification, and production and costs.

\section{LITERATURE CITED}

ANON. 1987. National Forest Inventory 11(1981-1982), Peninsular Malaysia. Forestry Department Headquarters of Peninsular Malaysia publication. 286p

Hazumi, K., Yoda, K., KoKawa, S., Kira, T., (1969): Production ecology of tropical rain forests in south-western Cambodia. I. Plant biomass. Nature and Life in South-East Asia. 6: 1-51

Kamaruzaman Jusoff and Abdul Haye Semall., (1993): Detection of logging disturbances using satellite imagery. Proc. of the South East Asian Regional Conference on Education and Research in Remote Sensing. UTM, Skudai, Johor. 17p

Kamaruzaman Jusoff and Mohd. Rasol Abd. MANAF., (1995): Satellite remote sensing of deforestation in the Sungai Buloh Forest Reserve, P. Malaysia. International Journal of Remote Sensing 16 (11): 1981 1997

Kira, T., Ogawa, H., Yoda, K., Ogino, K., (1967): Comparative ecological studies on three main types of forest vegetation in Thailand. IV. Dry matter production, with special reference to the Khao Chong rain forest. Nature and Life in South-East Asia 5: 74-149

U.N.E.S.C.O., (1978): Tropical forest ecosystem: A state of knowledge report. U.N.E.S.C.O., Paris, 683p

Wүатт-Sмітн, J., (1963): Manual of Malayan silviculture for inland forest. Malayan forest record No.22

(Received 7 August 1998)

(Accepted 10 December 1998) 